\title{
Attitudes of Students Living in Dormitories of Zahedan University of Medical Sciences Towards the Causes of Drug Addiction
}

\author{
Parvizreza Mir Lotfi ${ }^{1}$; Mani Javadimehr ${ }^{2, *}$; Mahdiye Adrome ${ }^{3}$ \\ ${ }^{1}$ School of Medicine, Zahedan University of Medical Sciences, Zahedan, IR Iran \\ ${ }^{2}$ Deptartment of Medical English, School of Medicine, Zahedan University of Medical Sciences, Zahedan, IR Iran \\ 3 Deputy of Education,Zahedan University of Medical Sciences, Zahedan, IR Iran \\ ${ }^{*}$ Corresponding author: Mani Javadimehr, Department of Medical English, School of Medicine, Zahedan University of Medical Sciences, Zahedan, IR Iran. Tel: +98-5433443261, \\ E-mail: javadimehr@gmail.com
}

Received: November 13, 2012; Revised: November 20,2014; Accepted: December 16, 2014

\begin{abstract}
Background: Health-threatening behavior is one of the most challenges of social and mental health, that most countries are involved somehow in it, and as a result widespread and severe problems are imposed on communities.

Objectives: The aim of this study was to assess the attitudes of students living in dormitories of Zahedan University of Medical Sciences towards causes of drug addiction.

Patients and Methods: In this study, 100 students (60 boys and 40 girls) living in dormitories (Kooser and Misagi) of Zahedan University of Medical Sciences were selected using the simple random sampling method. Data were collected by oral interview and participants were asked demographic, geographic and economic oral questions about their attitude towards causes of drug addiction. The interview was conducted by psychology experts and respondents' answers were recorded on tape recorder and then transcribed on papers, and finally the data were analyzed by SPSS (15).

Results: Different percentages of participants expressed different views about the causes of drug addiction. Results showed that $75 \%, 65 \%$, $55.5 \% 90 \%, 40 \%$ and $85 \%$, of participants believed being away from their parents, curiosity, unconsidered friendships, smoking, using drug at home, and easy accessibility were as major contributing factors involved in drug addiction, respectively, and the same factors underlie the student's involvement in addiction.

Conclusions: Many contributing factors of drug abuse obtained in this study can influence on tendency towards drug use for new students. It is evident that the period of residency in dormitories is one of the most critical periods in students' life. Thus, the concerned authorities take necessary measures to overcome the students' mental and social problems.
\end{abstract}

Keywords: Attitude; Trends; Addictive Behavior

\section{Background}

Health-threatening behavior is one of the most challenges of social and mental health, that most countries are somehow involved with it, and that imposes widespread and severe problems on communities (1). Addiction is a phenomenon that has existed since long ago in human society (2). Currently, the parallel development and increased indisputable scientific understanding and public awareness are still lacking. Addiction is not just an individual aspect, but it is a social harm and threatens their physical and mental health, social and economic aspects of society and irreversible adverse effects will cross the threshold (3). Opiates sometimes withdraw from their drug use and continue repeatedly or successively and this inability to withdraw completely in most addicts is an idea considered by scientists that drug abuse be rooted in the structure with its full consolidation and may be the determining aspect of behavior.

In fact, we can say that addiction or drug abuse has truly become a worldwide problem. Iran's geographical posi- tion being proximal to the world's largest opium- producing countries and its strategic position (best route for the transport of opium) exposed this country to higher risks of drug addiction (4). Despite many efforts in the past two decades to raise awareness of the harm and high-risk behaviors due to drug abuse, it has been increasing, especially among young people. One of the most common high-risk behaviors among youth is drug use and the risk of addiction $(5,6)$. Trauma and addiction as social problems affect health, economy, complexity of their specific cultural and national sovereignty, security and independence of our country (7). Due to its peripheral issues it can be argued that human values and our national identity are at risk (8). Substance abuse is always in the scope of human life and it has led to many problems, including a decline in general health, increased mortality, family and social damage, loss of educational and employment opportunities and increased rates of clashes with the judicial system also, led to a cycle of drug 
use, continuing damage and consequences of this problem are seen on next generation (9). Psychological and social damage can be too enormous to realize one's life and his family (10). Discrete rejection from friends, family relations, loss of respect and jobs are problems would be imposed on patients with opiate. Despite the extent and severity of these issues, preventive measures that can reduce the damage caused by substance abuse are not well-organized, and significant cost of investment in this area is not considered. Nevertheless, cost of materials to be spent only for the prevention and control measures, thousands or even millions of dollars in reserve can go ahead annually for the consequences of drug use in health, justice and welfare of children and families, and thereby productivity of job costing can be attained (11). In addition, due to inadequate funding on addiction field, appropriate preventive measure framework has not been organized. Despite many activities to control and reduce substance abuse carried out by various sectors, including government and non-governmental organization in several areas, including community, family, educational environment, due to lack of proper organization desired results have not been achieved and has led to waste of time, money and human resources (12). Many theories to describe how to adopt behaviors of guarantee, and or of public health threats have been provided by individuals (13). Many researchers have tested these theories with empirical evidence and logical reason, but they have not yet reached consensus on this issue, and they are trying to achieve a theory or a model that appears stronger than the other theories that can better justify safe or unsafe behaviors in people. Research shows that drug addiction is a multifaceted issue, and various psychosocial factors, culture and genetics are involved in this field. Since drug abuse is a complex issue and from psychological standpoint, it has different dimensions, and any encounter and intervention in this area requires action, and extensive research in various aspects of social, economic, cultural, and psychological subjects (14). However, while discussing about different diseases, preventive measures before treatment of the diseases are emphasized (1). In this context it is mentioned: "prevention of substance abuse requires identification of the causes and factors involved in it."

\section{Objectives}

This article aimed to examine the knowledge and attitudes of students living in dormitories of Zahedan University of Medical Sciences, Iran, towards the causes of drug abuse.

\section{Patients and Methods}

This cross-sectional qualitative study was performed on predetermined samples and designed to explore the risk factors of drug addiction among the students. Population of our study included one hundred voluntary students (60 boys 40 girls) of Kousar and Misagi Dormitories of Medical, Dental and Para Medical Colleges of Zahedan University of Medical Sciences. All ethical issues related to the work presented have been thoroughly considered. The study has received its prior approval from The Ethical Committee of Zahedan University of Medical Sciences and carried out under its full supervision with medical ethics registration no: 91-709/8/07/2012. All individuals that participated in this project signed their informed consent.

\subsection{Sampling Method}

All members of the study population were allotted serial numbers (1-100) and a sample frame containing ten groups was prepared. Each group of sample frame contained 6 boys +4 girls. A simple random sampling method was employed to select 6 ( 4 boys and 2 girls) samples through lottery from each group of sample frame. Each sample was asked with demographic, social and economic questions about one's attitude towards causes of trends of drug abuse. Data were collected during a period of six months through interviews conducted by psychology experts with students and respondent's answers were recorded on tape recorder and then transcribed on papers and were analyzed.

\section{Results}

In this study, a set of contributing factors of drug abuse obtained relieved. Seventy-five percent of the participants believed that being away from their parents as causes of drug addiction; $65 \%$ were known to have curiosity as a factor towards drug diversion; 55.5\% knew unconsidered friendship as an addiction factor; $90 \%$ of those interviewed stated that smoking inculcates daring in young people to use drugs; $40 \%$ believed using drug at home is an important factor in drug addiction $85 \%$ of individuals referring to the Zahedan City environment stated that easy accessibility to drug being as a contributing factor of drug addiction and the same factors underlie the student's involvement in addiction. Moreover, The participants stated that the depression of being away from family environment leads to addiction among students living in dormitories; $78 \%$ of those interviewed stated reason for tendency of students toward the synthetic drugs, is failure to identify and understand them; $40 \%$ of people believed that unawareness about the harmful effects of addictive substances is the cause of drug abuse; $80 \%$ of students participating in the study regarded family organization failure and failure related to loved one as an important factor in student attitudes toward drug addiction; $55 \%$ believed that $1 \%$ of the population of economy associated with drug addiction; and $65 \%$ referred to the cultural dimensions and poverty of students in the cultural field as underlying factors in drug abuse. In terms of gender no significant relationship between responders of boys and girls was observed. No significant difference was seen between attitudes of participants and age, social and economic conditions (Tables 1 and 2). 
Mir Lotfi P et al.

\begin{tabular}{lccc}
\hline Table 1. Reasons Provided by Both Girls and Boys Toward Drug Abuse Attitude & & & \\
\hline Reasons offered by study samples toward drug abuse attitude. & & Frequency \\
\cline { 2 - 4 } & Girls & Boys & Total \\
\hline Staying away from home & 15 & 30 & 45 \\
Curiosity about drug abuse & 13 & 26 & 39 \\
Unconsidered friendship & 11 & 22 & 33 \\
Smoking before drug abuse & 18 & 36 & 54 \\
Family history of addiction & 8 & 16 & 24 \\
easy access ability of Zahedan city environment & 17 & 34 & 51 \\
Depression & 11 & 22 & 33 \\
Failure to identify and understand drug industries & 16 & 31 & 47 \\
Unawareness of adverse effects of addicting drugs & 16 & 24 \\
\hline Disruption of family organization and love failure & 32 & 48 & 40 \\
\hline 1\% of population of economy associated with drug addiction & 22 & 33 \\
\hline Poverty of culture & 26 & 39 \\
\hline
\end{tabular}

a Data are presented as No.

Table 2. Comparison of Drug Abuse Attitudes of Boys and Girls with Age, Social and Economical Conditions ${ }^{\text {a }}$

\begin{tabular}{lcc}
\hline Variables & Girls & Boys \\
\cline { 2 - 3 } & $\mathbf{2 2 - 2 4 ,} \mathbf{y}$ & $\mathbf{1 9 - 2 4 , \mathbf { y }}$ \\
\hline Social status, Point & 10 & 10 \\
Good & 3 & 8 \\
Bad & 27 & 37 \\
\hline Moderate & & \\
Economical status, Point & 7 & 10 \\
Good & 3 & 5 \\
Bad & 30 & 45 \\
\hline Moderate &
\end{tabular}

${ }^{\mathrm{a}} \mathrm{P}$ value obtained for the Chi- square test is $\mathrm{P}<0.05$.

\section{Discussion}

Many contributing factors of drug abuse obtained in this study reveal that the new students are likely to tend towards drug abuse. Psychological and social damage incurred due to drug abuse is irreversible $(15,16)$. Despite the many efforts to control and reduce substance abuse deployed by various sectors, because of lack of proper management desired results have not been attained and has resulted in waste of time, money and human resources (16). Students are considered as one of the most important target groups for behavioral training, which constitute a large part of the country's population, so that population ratio in this group has social potential vulnerability more than vulnerability of society (17). On the other hand, Universities are places suitable for providing educational programs to promote health and prevent high-risk behaviors (18).

It is evident from our study; the period of residency in dormitories is one of the most critical periods in students' life. Many contributing factors of drug abuse obtained in this study can influence on tendency towards drug use for new students. The concerned authorities have to take necessary measures to overcome the student's mental and social problems, and they should also inform students more about drugs and the risks of drug abuse. Certain implications, knowledge of addictive substances and preparation and distribution of educational CD for students are recommended. Students and their families in collaboration with the Center for Combating Drugs, hold workshops in order to strengthen students' psychological vigor, and employ supervisors to train students to deal with addiction can be contributing parts of this issue. Allegedly, it has been said three basic ways namely fighting against supply, treatment of addicts, and preventive activities to reduce the drug abuse are recommended. Though our study findings can be considered when planning substance preventive programs as effective to dormitory students of Zahedan University of Medical Sciences, besides rapid assessment surveys, there is a demand to carry out in-depth studies that address the root causes of drug abuse.

\section{Acknowledgements}

We would like to acknowledge and thank Mrs. Rogieh Javadi who provided technical help and writing assistance and we also thank departmental head that provided general support. Our thanks go to students that agreed to give their informed consent and volunteered with patience to take part in this research project.

\section{Author Contributions:}

Study concept and design: Parvizreza Mirlotfi, Drafting of the manuscript: Mani Javadimehr, Interpretation 
of data: Mahdieh Adrome, Critical revision of the manuscript for important intellectual content: Parvizreza Mirlotfi, and Mani Javadimehr.

\section{References}

1. Manandhar K, Chataut J, Khanal K, Shrestha A, Shrestha S, Shrestha $S$. Awareness regarding preventive measures of avian influenza among the adult people of Thimi Municipality, Nepal. Kathmandu Univ Med J (KUMJ). 2013;11(41):45-9.

2. Berg CJ, Schauer GL, Buchanan TS, Sterling K, DeSisto C, Pinsker EA, et al. Perceptions of addiction, attempts to quit, and successful quitting in nondaily and daily smokers. Psychol Addict Behav. 2013;27(4):1059-67.

3. Hatou K. [Mental Health Atlas 2011 (WHO)]. Seishin Shinkeigaku Zasshi. 2014;116(4):267.

4. Krajko G, Dobronte Z, Meszaros R. [Connection between the geographic position of settlements and the mobility of population in the Southern Plain]. Foldr Ert. 1978;27(3-4):415-31.

5. Xu J, Shen LX, Yan CH, Hu H, Yang F, Wang L, et al. Parent-adolescent interaction and risk of adolescent internet addiction: a population-based study in Shanghai. BMC Psychiatry. 2014;14:112.

6. Altaf A, Shah SA, Zaidi NA, Memon A, Nadeem ur R, Wray N. High risk behaviors of injection drug users registered with harm reduction programme in Karachi, Pakistan. Harm Reduct J.2007;4:7.

7. Cross CL, Ashley L. Trauma and addiction: implications for helping professionals. $J$ Psychosoc Nurs Ment Health Serv. 2007;45(1):24-31.

8. Angerer J, Aylward LL, Hays SM, Heinzow B, Wilhelm M. Human biomonitoring assessment values: approaches and data require- ments. Int J Hyg Environ Health. 2011;214(5):348-60.

9. Guha M. Urea cycle disorder drug approved. Nat Biotechnol. 2013;31(4):274.

10. Masling J, Lewis P. The social psychology of the use of psychological tests to predict brain damage. J Proj Tech Pers Assess. 1966;30(5):415-7.

11. Wade N. Testing genes to save a life without costing you a job. The New York times on the Web; 1997.

12. Abraham S. Acquisition and allocation of human, financial, and physical resources in the health care system. Health Care Manag (Frederick). 2011;30(1):38-44.

13. Wilson K, Gardam M, McDougall C, Attaran A, Upshur R. WHO's response to global public health threats: XDR-TB. PLoS Med. 2007;4(7):e246.

14. Jerabek I, Boulenger JP, Bradwejn J, Lavallée YJ, Jolicoeur FB. CCK 4-induced panic in healthy subjects I: psychological and cardiovascular effects. Eur Neuropsychopharmacol .1999;9(1-2):149-55.

15. Chaudhary NS, Chakravorty S, Evenden JL, Sanuck N. Insomnia severity is associated with decreased executive functioning in patients with suicidal ideation and drug abuse. Prim Care Companion CNS Disord. 2013;15(5)

16. Report of the Expert Group on Drug Abuse Reduction. Bull Narc. 1983;35(3):3-17

17. Aydin C, Oztan O, Isgor C. Vulnerability to nicotine abstinencerelated social anxiety-like behavior: molecular correlates in neuropeptide Y, Y2 receptor and corticotropin releasing factor. Neurosci Lett. 2011;490(3):220-5.

18. El Ansari W, Stock C, John J, Deeny P, Phillips C, Snelgrove S, et al. Health promoting behaviours and lifestyle characteristics of students at seven universities in the UK. Cent Eur J Public Health. 2011;19(4):197-204. 